\title{
El cosmopolitismo de María Zambrano y Alfonso Reyes
}

The Cosmopolitanism of Maria Zambrano and Alfonso Reyes

Julieta Lizaola Universidad Nacional Autónoma de México julieta.lizaola@gmail.com

DOI: https://doi.org/10.15366/bp2020.25.005

Bajo Palabra. II Época. No25. Pgs: 117-128 


\section{Resumen}

El presente texto perfila una visión compartida sobre la importancia de ser ciudadanos del mundo, de ejercer el cosmopolitismo como forma de defensa de lo diverso, de lo heterogeneo. En esta premisa reside la aceptación y reconocimiento de la multiplicidad de elementos que conforman la vida subjetiva y social de la persona, del ciudadano. Este vinculo es el centro de la relación epistolar entre María Zambrano y Alfonos Reyes que en la amplitud de su perspectiva poética y filosófica les permite afirmar lo distinto, lo diferente, en términos culturales y políticos.

Palabras clave: cosmopolitismo, cultura, persona, ciudadano.

\section{Abstract}

This text outlines a shared vision of the importance of being citizens of the world; in other words, of exercising cosmopolitanism as a form of defense of the diverse, of the heterogeneous. Within this premise resides the acceptance and recognition of the multiplicity of elements that make up the subjective and social life of the person, the citizen. This link is at the center of the epistolary relationship between María Zambrano and Alfonso Reyes, which from their deeply poetic and philosophical perspective allows them to affirm what is different in cultural and political terms.

Keywords: cosmopolitanism, culture, person, citizen. 
La piedad ha cumplido su oficio... ha nacido la conciencia y con ella una inédita soledad. Entonces comienza la verdadera historia de la libertad y el pensamiento.

María Zambrano

\section{I}

La consolidación del Estado Nación estableció un espacio de poder y con ello la instauración de la hegemonía de lo homogéneo. Implantó, entre otras cosas, la preocupación por la identidad nacional, por lo "propio". Algo que hoy día se aparece con fuerza renovada en varias partes del mundo, evidenciando que aún estamos bajo esta concepción que no sólo incide en la vida política, sino que también lo hace en la vida moral de las sociedades. Concepción de dominio que aspira a lo uniforme, a lo unívoco, a lo asimilado y permanente. A aquello que se perturba ante la un anhelo o concepción no permitida, no autorizada; ha impedido así, la conformación de la persona; es decir, la construcción de un sujeto político y ético que asuma la responsabilidad que como ciudadano le corresponde. Las diversas formas de enajenación social se dirigen a la uniformidad como intención política y cultural. Como nos recuerda Ambrosio Velasco: "La diversidad cultural es hoy en día uno de los más importantes retos de las sociedades contemporáneas y uno de los problemas más significativos de las ciencias sociales y las humanidades". ${ }^{1}$

En la relación epistolar que sostienen María Zambrano y Alfonso Reyes, escritor y pensador mexicano, se observa que comparten miradas, puntos de vista, sobre cuestiones medulares que guardan relación con la defensa de la diversidad como principio: la primera, consideran que el amor por la poesía, la literatura y la filosofía, es un saber de unidad infragmentable e irreductible; la segunda, y que aquí subrayamos, es su aspiración e intención por mostrar la complementariedad de lo

\footnotetext{
Velasco, A., Aspectos epistemológicos, hermenéuticos y politicos de la diversidad cultural, México, UNAM, 2014, p. 9.
} 
diverso, de lo múltiple y de lo heterogéneo, en lo universal. Son dos espíritus que desean que la amplitud de su perspectiva poética y filosófica los lleve a afirmar lo distinto, lo diferente, en términos culturales y políticos. Este punto será decisivo para ambos: la aceptación de que el mundo es un lugar heterogéneo donde todas las personas y los pueblos deberían por igual hacer valer sus culturas, sus concepciones del mundo, sin que éstas sean susceptibles de ser negadas. "Una cultura debe tener las condiciones para reproducir y adaptar sus formas de vida de manera original, partir del núcleo mítico y ético que la identifica." ${ }^{2}$

\section{II}

En los postulados que desarrolla María Zambrano en su libro Persona y Democracia son las personas las que pueden alcanzar una concepción cosmopolita, las que se inclinan a vivir la diversidad, pues tienen clara la importancia de la presencia del otro, del reconocer al otro, y de desear un mundo donde todos sean polites, ciudadanos. Ciudadanos que comparten la responsabilidad que han asumido en tanto tales, respecto a la ordenación de Polis, del bien común, de la nación, de la patria. Un mundo cosmopolita es un lugar donde todos tienen cabida.

La sociedad conformada por personas es una tarea, un proceso a cumplir, un desarrollo que se corresponde con una concepción intelectual, ética y estética. En ella el arte ocupa un papel preponderante ya que renueva la percepción de las cosas, abre los sentidos, suprime la condición de fijeza que nos oprime y nos aliena. Por ello Zambrano y Reyes colocan al arte en punto central del despliegue del espírtu humano.

Se descubre en el arte [...] el empeño de reencontrar la huella de una forma perdida no ya de saber solamente, sino de existencia; [...] Testimonio de que el hombre ha gozado [...] de un vivir diferente, dentro de un espacio y un tiempo propios, dentro de un lugar central y no en la periferia, cuando los rayos divergentes no se habían separado aún. ${ }^{3}$

Por lo mismo, resultan de fundamental relevancia las políticas culturales que se implementan asumiendo como propios los vínculos entre pueblos heterogéneos. Políticas culturales que se sostienen sobre una concepción de respeto, la más opuesta posible al "ímpetu de expansión e implantación de una cultura en detrimento

\footnotetext{
2 Subirats, E., Entrevista: "Vivimos en una edad antiartística", p. 205-207. FFyL/Investigación/Publicaciones/ Revistas/Graffylia/Graffylia No. 18s

3 Zambrano, M., Obra Reunida, Madrid, Ed. Aguilar, 1971, p. 221.
} 
de otra" ${ }^{4}$. Así lo concibe Alfonso Reyes en la primera mitad del siglo xx, quien no duda en diseñar un cosmopolitismo basado en lo que a su entender es la experiencia y el papel del continente americano, en específico del latinoamericano, sosteniendo un diálogo necesario y permanente con el espíritu del humanismo renacentista, es decir, con múltiples y diferentes anhelos de conocimiento poético, filosófico, científico y artístico. La empresa cosmopolita humanista "sólo quiere facilitar la circulación del hombre dentro del mundo humano, desarrollar el conocimiento y la comprensión de los pueblos". 5

El cosmopolitismo que acuñó el escritor mexicano apuntaba a la defensa de un trabajo intelectual que contribuyera a deliberar sobre la diversidad y su insustituible articulación. De ahí que, aclare Reyes que "la unificación no significa la renuncia a los sabores individuales de las cosas, .... que la vida ha de ofrecer para ser vida" ${ }^{6}$

Por su parte Zambrano, a menos de un año de haber iniciado su exilio en México en la ciudad de Morelia, se traslada a La Habana, lugar donde permanecerá por más de 10 años. Esto le permite entrar en contacto con varios intelectuales y movimientos artísticos de la isla; el más relevante de estos y del cual quedará honda huella en su obra, es el de Orígenes. Grupo plural de escritores, pintores, músicos, poetas que reunía a lo más relevantes de la vida artística cubana. Por lo que ella misma dejó ver en diferentes cartas y textos, le fue fácil adentrarse al grupo y formar parte de él. Podemos subrayar que en éste se encontraba Lezama Lima, figura singular y fundamental para ella durante y después de su vida en Cuba, central también para construir su red de fundamentación filosófica cuya clave, en sus propias palabras, será el orfismo pitagórico. Ambos, órficos y pitagóricos, sabrán de sobra lo esencial que es descender a los ínferos a encontrar al otro como actividad nuclear del pensamiento y del arte, pues aquello que nos conduce al conocimiento es el amor; el amor mueve al amante hacia lo amado para recuperarlo y afirmarlo. La incorporación de Zambrano a la vida de Orígenes le dará acceso a es a Cuba secreta donde se mantiene vivo el anhelo estético y ético de la vida. En palabras de Francy Moreno:

Las políticas cosmopolitas de Origenes, por su parte, combinaron los intereses de sus directores, José Lezama Lima y José Rodríguez Feo. El primero, estaba empeñado en la formación de un grupo poético creativo, [...]. El primer editorial de Orígenes, nos propor-

\footnotetext{
${ }^{4}$ Moreno, F., "Universalismo, cosmopolitismo y política editorial en revistas culturales del siglo xx", Revista de estudios Latinoamericanos, Volumen 64, México, UNAM, 2017, p. 100. https://doi.org/10.22201/cialc.24486914e.2017.64.55057

5 Reyes, A., "Atenea política", en Tentativas y orientaciones, recogido en Obras completas, XI, México, FCE, 1970, pp. 190 y 191.

${ }^{6}$ Moreno, F., "Universalismo, cosmopolitismo y política editorial en revistas culturales del siglo xx", op. cit., p. 102.
} 
ciona las mejores luces sobre las fuerzas que quería atraer con su política universalista y cita: "aquellas fuerzas de creación, de todo fuerte nacimiento donde hay que ir a buscar la pureza o impureza, la cualidad o descalificación [...] siempre que se manifieste dentro de la tradición humanista, y la libertad que se deriva de esa tradición”. Como se puede inferir de la cita, se trataba de algo más complejo que simplemente reunir diferentes artistas, Lezama Lima quería generar procesos creativos, producir materiales inéditos. Su apuesta tuvo éxito y después de ocho años de publicar Orígenes, en la nota "Alrededores de una Antología", el autor de Paradiso pudo ufanarse del éxito de lo que llamó un "intento de universalización", como "signo esencialísimo de Orígenes". Los argumentos que sustentaban esos logros se fundaron en que la revista había publicado nombres reconocidos como George Santayana o Wallace Stevens, Vicente Aleixandre, Octavio Paz, T. S. Eliot. Las figuras señeras que respaldaron la apuesta poética, que tuvo como centro a Lezama Lima, fueron Juan Ramón Jiménez y María Zambrano. [...] Se realizaron intercambios con el grupo Sur en Buenos Aires y con algunos sectores de los intelectuales mexicanos y espańoles. Todo ello muestra del interés por extender lazos a lo largo de Latinoamérica y con poetas ibéricos." 7

Queremos poner de relieve que la política editorial de Orígenes se correspondía con el interés de Zambrano por establecer lo heterogéneo, lo heterónomo, como lo que funda y da lugar a elementos de cultura, como la realidad natural del pez en el agua. Por ello no es de extrañar que su búsqueda, culturalmente abierta y diversa, fuera capaz de interrelacionarse con la de diferentes grupos. Podemos observar tanto en su biografía como en su construcción teórica la importancia decisiva que guarda lo que denomina "la relación con lo otro". Esa relación piadosa con el mundo que contempla la multiplicidad y diversidad de las cosas y se niega a la reducción de la realidad a un solo horizonte.

\section{III}

El intercambio epistolar entre María Zambrano y Alfonos Reyes culmina con la celebre Carta Abierta a Alfonso Reyes escrita en Roma en el año de 1954 y fue publicada en El papel literario de Caracas. Con antelación Reyes había publicado dos artículos sobre Goethe en ese mismo periódico, el primero fue: "Breve Biografía de Goethe" (10 de mayo de 1954) y el segundo, "El supuesto olimpismo de Goethe" (en dos partes, 7 y 14 de junio de 1954).

En esa "Carta abierta" va y viene, se pesa y sopesa, —considera Adolfo Castañón, quien es un gran estudioso de la obra de ambos pensadores- el presunto olimpismo de Goethe - y entre líneas y por acallada extensión, el talante aristocrático del propio Alfonso Reyes, se-

${ }^{7}$ Ibid., p. 110. 
gún Zambrano por implicación [...] El “olimpismo” —continua Castañón- aflora como una fórmula para debatir la altura, la distancia, la elevación como de torre de marfil del alemán, quien, [...] en el razonamiento de María Zambrano, no habría sabido pagar el precio sacrificial de su propia creación y habría, buen padre del Fausto, engañado al propio demonio. "El supuesto olimpismo de Goethe" fue escrito y publicado por Alfonso Reyes en 1954 -el mismo año sale a la luz el breviario "Trayectoria de Goethe"; ahí repasa la cuestión sobre la distancia del escritor en relación con la sociedad y sobre todo con la propia vocación. ${ }^{8}$

Recordemos que a Goethe se le había acusado de olimpismo, por mantener en su obra una enorme distancia con la realidad, de ser un intelectual lejano a los acontecimientos de su época. De igual forma, a Reyes se le acusaba mantenerse incólume y de no involucrarse en los sufrimientos propios de la sociedad mexicana, de no interesarse en sus temas de trabajo por reflexionar sobre la situación mexicana; "la acusación de poca conexión entre los escritos del alemán y su realidad circundante molestó siempre a Reyes," ${ }^{9}$ Y como lo documenta y muestra Virginia Aspe en su análisis sobre Alfonso Reyes, es una afirmación equivocada. Para probar esto se dirige a dos cuestiones específicas: una, su ensayo La visión de Anáhuac y dos, su ensayo filosófico El deslinde. Este último es donde la autora piensa que se sostiene una postura filosófica avanzada e incomprendida por sus contemporáneos, (a quienes no convenció de su compromiso con el momento histórico de su vida) Sin embargo, la identificación que se supone mantuvo con Goehte, y su acusación de olimpismo, será la que le permita elaborar el trato filosófico con su contexto mexicano e iberoamericano. Concepción que no fue perclbida en su momento por la vida intelectual mexicana y en la que Virginia Aspe pone el acento.

Reyes no fue comprendido como filósofo porque se anticipó a su tiempo, allí donde se buscaba especulación y argumentaciones noéticas, el regiomontano se propuso reflexionar sobre las diferencias y las demarcaciones. El Deslinde no es el título de una obra sino un género filosófico que instauró anticipando un nuevo modo de hacer filosofía, filosofía de fronteras, en donde el método consiste precisamente en separar; filosofía de la diferencia, algo que hoy nos resulta familiar por el discurso filosófico de un Vattimo, Derridá, Lyotard o Foucault, pero que en los ańos cuarenta del siglo pasado era aún inimaginable. En Reyes, se instaura un nuevo género filosófico donde el objeto material no es el ser sino la literatura teniendo como sentido la ficción, la intención y el empréstito. Si el ser griego estaba validado por el tema de lo en sí y del hogar, el género filosófico alfonsino se inserta en lo medial, lo relativo y metafórico, se estudia la ficción y la verosimilitud poética. ${ }^{10}$

\footnotetext{
${ }^{8}$ Castañón, A., Revista Letras Libres 85, junio 2006. https://www.letraslibres.com/mexico/libros/dias-exilio-correspondencia-entre-maria-zambrano-y-alfonso-reyes-1939-1959

9 Aspe, V., Enciclopedia electrónica de Filosofía mexicana. http://dcsh.izt.uam.mx/cen_doc/cefilibe/images/banners/enciclopedia/Diccionario/Autores/OtrosFilosofos/Reyes_Alfonso-AspeArmellaVirginia.

${ }^{10}$ Ibid., pp. 18-19.
} 


\section{María Zambrano, en su ya mencionada Carta Abierta a Alfonso Reyes sobre Goe-}

the, se adentra en este terreno, en el de la distancia o cercanía de un autor con su momento histórico, lo cual para ella es un compromiso insoslayable e irrenunciable: pues deriva de algo que está en el núcleo del escritor, del pensador, del artista, y sólo puede ser resultado de "saber tratar con lo otro", con lo diverso, con aquello que le permite adentrarse realmente en el centro viviente del ser de las cosas. Escuchemos a Zambrano:

No sé, naturalmente, si lo que me pasa con Goethe coincide con el sentir de los que han fabricado y mantenido el tópico de su "olimpismo". No puedo hablar sino en nombre propio, preguntándome qué raíz tiene ésta, más que aversión, resistencia a dejarme anexionar por uno de los más lúcidos espíritus del mundo al que pertenecemos [...] ¿ Es la pluralidad del alma, quizá, la pluralidad de almas fundidas en un solo destino, enseñoreadas por una sola voluntad, lo que despierte una especie de rencor en quienes harto habemos con el peso de nuestra sola, única alma? Ya ve que estoy entrando en el terreno de la confesión, que ya aludo a cosas secretas e indescifrables de mi propio ser, pues ¿̇sé yo acaso qué género de unidad poseo? [...] Y, ¿por qué?, me pregunto; ¿por qué nunca me he dejado seducir por el brillo que irradia la figura de Goethe? ¿Por qué no puedo decir sin faltar a la verdad que me haya alimentado de su pensamiento, que me haya sido imprescindible como Nietzsche - por citar filósofos-poetas solamente- que me haya atraído como Schiller; que me haya despertado ese sentimiento que es ligazón fraternal, como Hölderlin y Novalis - por referirme tan sólo a otros hijos de su mismo suelo germánico? ¿Por qué? No ciertamente porque la obra de Goethe carezca de riquezas innumerables, quizás demasiado innumerables... pero ahí está Nietzsche que también las posee y en forma ambigua y para muchos perturbadora. Nietzsche también tuvo varias almas; la unidad de su espíritu también se dio en la metamorfosis. Entonces, mirando lo que de común tienen los cuatro poetas-filósofos que he enumerado algo que parece en todos y más determinadamente en dos de ellos -Nietzsche y Hölderlin- y que no se deja ver en Goethe, algo, sí, difícil de decir ahora que lo he encontrado [...] Creo haber descubierto que el motivo de mi resistencia ante tan grande espíritu es simplemente el que no haya sido criatura de excepción, sacrificado o raptado por los dioses en alguna forma.

Veamos si puedo explicarme. Creo que lo que me sucede ante el caso de Goethe, ese hombre que parece haberse escapado de pagar la prenda — la prenda que de nińos aprendemos a jugar, a pagar- es una zozobra que traducida en pregunta sería: ¿ ¿ cómo, si es posible lograrse como hombre en tanto esplendor no acontece así más a menudo? ¿Por qué la plenitud goethiana es un "caso" y no la normalidad en mayor o menor escala? Y no se le ocultará que bajo esa pregunta late la angustia de estos tiempos en que el humanismo ha hecho quiebra; pues hoy nos preguntamos en mil formas, hasta cuando nos preguntamos otra cosa: ¿Es que es posible ser hombre? ${ }^{11}$

11 Negrita nuestra. 
[... ¿Cómo consiguió su plenitud sin pagar prenda? [...] Y mal sagrado el de Hölderlin; sagrada también la miseria de nuestro don Miguel, que tuvo hasta su estigma en la mano mutilada. Y estigma también la sordera de Beethoven y los vértigos de Pascal. ¿De qué se valió Goethe para pasar sin estigma ni pagar prenda? ¿Es que acaso tan grande poeta era, y adivino, no tuvo que ver nada con lo sagrado, con la piedad? Y como los dioses olímpicos parecen ser la esencia inmutable en su perenne metamorfosis que trasciende la piedad antigua -que es estigma y pagar prenda-, de ahí que quizá el olimpismo que circunda como un halo y como un estigma, a Goethe $[\ldots]$

Todo hace pensar en un pacto. Y puesto que, de aquí, de Roma, volvió tan cambiado, lleno de serenidad y fuerza, maestro de sí mismo, como usted tan delicada y agudamente señala, por qué no pensar que algo aprendió aquí de lo que más le importaba: una ciencia de la piedad que es "saber tratar lo otro" -lo pongo entre comillas porque me veo forzada a citarme a mí misma. Saber tratar, sí, con lo diverso, con los distintos planos de la realidad que al ser armonía ha de ser múltiple. ${ }^{12}$ Saber tratar con lo cualitativamente diferente: tender puentes entre los abismos existenciales, que hoy se diría..."13

Esta larga cita que recorta la Carta Abierta, quiere rescatar lo que permite entender la postura de Zambrano frente a Goethe. Esa petición de tender el puente, para recoger el agua del pozo, sobre todo por las noches, ${ }^{14}$ es la petición de Zambrano a Goethe. Es su queja el no dar cuenta de los hermanos que si pagaron prenda, que si fueron víctimas de algún sacrificio. Que si trataron con lo otro: con la Piedad. También, cabe señalar, está presente en la Carta algo más que una puntualización casual sobre un autor.

En esa carta abierta, advierte Adolfo Castañón, -abierta para que le dé el aire de la discusión- están jugándose con Goethe y alrededor de él -pero también hacia Reyes y a su alrededor- dos asuntos mayores del debate crítico y filosófico de nuestra edad: el de la vocación poética y filosófica, no como un llamado a la especialización, sino a la integración de las distintas tentaciones intelectuales. ${ }^{15}$

La integración de la poesía, la filosofía y la religiosiad es una constante en las reflexiones de la autora. Desarrolla en varias partes de su obra argumentaciones rigurosas sobre cómo, sin estos elementos inalienables de la vida humana, es imposible comprender el desarrollo de la espiritualidad del hombre, por lo que los

\footnotetext{
12 Ibid.

13 Enríquez Perea, A., Días de exilio. Correspondencia entre María Zambrano y Alfonso Reyes. México, Ed. El Colegio de México, Ed. Taurus, 2005, pp. 250-25. (Negrita nuestra).

${ }_{14}$ Zambrano, M., “Carta abierta a Alfonso Reyes sobre Goethe”, en Enriquez Pera, Alberto, op. cit., p. 254.

15 Castañón, A., op. cit.
} 
intentos por reducir o negar alguna de estas dimensiones es un atentado no sólo contra el conocimiento sino, aún más, contra la posibilidad de la continuación de la vida. Elementos vitales, que algunas mentalidades reductivistas y casi ciegas no han podido reconocer, no podido ver como entre las brumas aparece la posibilidad del humanismo que no deslindó a la poesía del conocimiento, ni de la sabiduría: "En su profunda infinitud vi internarse, unidas por el amor en un volumen, las hojas desperdigadas de todo el universo..." 16

María Zambrano no podía dejar de ver -y de hecho lo expresa - que algo en Goethe (y en Alfonso Reyes) se le escapaba. Y eso que se le escapaba - ella lo intuía - estaba hecho de la misma materia que estas cartas: era y es el sacrificio, el no guardarse prendas para sí, el hacer todo lo posible para que el otro, la otra, pueda seguir su camino gracias a que alguien cumplió su palabra. María Zambrano no podía dejar de admirar esa voluntad de cumplimiento y de acto que infunde a la figura de Alfonso Reyes su "plástica rotundidad". Por no haber escamoteado el pago de lo demoniaco que, como recuerda María Zambrano en la Carta abierta ..., no eludieron pagar ni Hölderlin ni Nietzsche. La "carta abierta a Alfonso Reyes" tendría además otra función: la de defender y encarecer al propio Alfonso Reyes, en vida, como una figura señera y acreedora de toda gratitud y admiración por parte de la inteligencia peregrina. ${ }^{17}$

La piedad zambraniana es el trato con lo otro, la aceptación de lo múltiple y diverso que compone la realidad. Su oficio es ayudar a nacer a la conciencia en lo otro, en lo que es diferente, lo que no es, en lo que no se da a simple vista, sino que hay que hacerlo visible. La piedad no es sino la forma originaria del sentir frente a la amplitud de una realidad en su heterogeneidad, compuesta de un cúmulo de realidades y tiempos. Es un camino para entender lo otro, una forma de acción para conocerlo. La piedad es preminente a la fuerza, y es imprescindible para guiarnos por la deshonra del mundo y sus realidades disminuidas, diluidas, hechas menos; para salir de ello, para sacudirse la infamia, es necesaria la piedad pues es con ella que la persona actúa dentro de la diversidad que se requiere para ser ciudadano del mundo, para ser cosmopolita, para dejar de lado la larga noche sacrificial.

La democracia es hoy el «único camino para que prosiga la llamada cultura de Occidente y esta revelación pone al descubierto, hoy más que antes, la estructura sacrificial de la historia humana». Como no se puede hablar ya en términos de un sacrificio tradicional, otra es su manifestación para el nacimiento del nuevo hombre que requiere Occidente. Es por ello que ya no se trata de una crisis, sino de una "orfandad", como la cataloga Zambrano. Las palabras con las que se cierra el libro proponen la necesidad de arrojar la máscara que cubre al hombre

\footnotetext{
${ }^{16}$ Alighieri, D., La divina comedia. Paraíso, Canto xxxıII, 87.

17 Castañón, A., op. cit.
} 
occidental para renunciar a ser personaje dentro de la historia y elegirse como persona que, a su vez, sepa elegir a los demás hombres aceptando, por fin, al otro en toda su realidad. ${ }^{18}$

\section{IV}

En síntesis, observamos que la correspondencia entre Zambrano y Reyes enriquece la reflexión sobre el mundo contemporáneo. Un mundo que entiende el proyecto civilizatorio bajo una lógica de negación y destrucción, dónde cabe la pregunta que formula abiertamente Zambrano: ¿Es posible todavía ser un hombre? La respuesta parece dibujarse en la posibilidad de aproximarnos a un humanismo crítico que sostiene una articulación permanente con el espíritu renacentista: con el que acepta la diversidad ontológica del mundo y sus diversas formas de conocimiento, sin intentar imponer ningún proceso epistémico, sin destruir ninguna singularidad. Será el amor por el arte y por un mundo diverso y heterogéneo lo que una la poética intelectual de Reyes y Zambrano.

Saber tratar con la mujer, el loco y el enfermo; saber tratar con el mundo que es siempre "lo otro" - el no-yo-. Saber tratar con lo sagrado, poniéndose una máscara cuando hace falta callar a tiempo; saber de conjuros y de exorcismos; poder descender a los infiernos una y otra vez y hasta saber morir en vida todas las veces que haga falta. Saber tratar con los muertos y con sus sombras. Y sobre todo, sobre todo, saber tratar con "lo otro" en sentido eminente: "El Otro". ${ }^{19}$

\footnotetext{
${ }_{18}$ Muñiz-Huberman, A., "María Zambrano”, Letras Libres, 20, 2003. https://www.letraslibres.com/mexico-espana/maria-zambrano

19 Zambrano, M., "Carta abierta a Alfonso Reyes sobre Goethe”, op. cit. p. 254.
} 


\section{REFERENCIAS BibLIOGRÁficas}

Alighieri, D., La divina comedia, Paraíso, Canto XXXIII, 87.

Aspe, V., Enciclopedia electrónica de Filosofía mexicana. http://dcsh.izt.uam.mx/ cen_doc/cefilibe/images/banners/enciclopedia/Diccionario/Autores/OtrosFilosofos/Reyes_Alfonso-AspeArmellaVirginia.

Castañón, A., "Días de exilio. Correspondencia entre María Zambrano y Alfonso Reyes", Revista Letras Libres, 85, junio 2006. https://www.letraslibres. $\mathrm{com} / \mathrm{mexico} / \mathrm{libros} /$ dias-exilio-correspondencia-entre-maria-zambrano-y-alfonso-reyes-1939-1959

Enriquez Perea, A., Días de exilio. Correspondencia entre María Zambrano y Alfonso Reyes, México, Ed. El Colegio de México, Ed. Taurus, 2005.

Moreno, F., "Universalismo, cosmopolitismo y política editorial en revistas culturales del siglo xx", Revista de estudios Latinoamericanos, v. 64, México, UNAM, 2017. https://doi.org/10.22201/cialc.24486914e.2017.64.55057

Muñiz-Huberman, A., "María Zambrano", Letras Libres No. 20, 2003. https:// www.letraslibres.com/mexico-espana/maria-zambrano

Subirats, E., Entrevista: "Vivimos en una edad antiartística”, p. 205-207. FFyL/ Investigación/Publicaciones/Revistas/Graffylia/Graffylia No. 18

Reyes, A., "Atenea política", en Tentativas y orientaciones, recogido en Obras completas XI, México, FCE, 1970, pp. 190 y 191.

Velasco, A., Aspectos epistemológicos, hermenéuticos y politicos de la diversidad cultural, México, UNAM, 2014.

Zambrano, M., Obra Reunida, Madrid, Ed. Aguilar, 1971.

Zambrano, M., Persona y democracia. La historia sacrificial, Madrid, Ed. Siruela, 2004.

DOI: https://doi.org/10.15366/bp2020.25.005

Bajo Palabra. II Época. No25. Pgs: 117-128 